\title{
Observation of a stripping threshold for the reaction $\mathrm{N}_{2}^{+}+\mathrm{CH}_{4} \rightarrow \mathbf{N}_{2} \mathrm{H}^{+}+\mathrm{CH}_{3}$
}

\author{
J. R. Wyatt, ${ }^{*}$ L. W. Strattan, ${ }^{\dagger}$ S. C. Snyder, ${ }^{\ddagger}$ and P. M. Hierl
}

Department of Chemistry, University of Kansas, Lawrence, Kansas 66045

(Received 11 April 1975)

\begin{abstract}
Chemical accelerator studies on isotopic variants of the reaction $\mathrm{N}_{2}^{+}+\mathrm{CH}_{4} \rightarrow \mathrm{N}_{2} \mathrm{H}^{+}+\mathrm{CH}_{3}$ are reported. Reaction cross sections, as well as velocity and angular distributions of the ionic products have been measured as a function of initial translational energy over the range $0.65-35 \mathrm{eV}$ (center of mass). The results are similar to those recently reported for the reaction of $\mathrm{Ar}^{+}$with $\mathrm{CH}_{4}$. The excitation function maximizes at about $5 \mathrm{eV}$ (c.m.) and decreases at lower collision energies, appearing to possess a threshold at $0.1 \mathrm{eV}$. At the higher energies there is a large isotope effect favoring abstraction of $\mathbf{H}$ over $\mathrm{D}$. The product velocity vector distribution is strongly peaked forward of the center of mass, indicating that the reaction is predominantly direct over the energy range studied. The spectator stripping model, although providing a reasonable first approximation to the reaction dynamics, overestimates the product translational energy by approximately $0.1 \mathrm{eV}$. This behavior is presumed to be caused by a basin in the potential energy hypersurface for this reaction. If, however, an $\mathrm{N}_{2} \mathrm{CH}_{4}^{+}$complex is formed at low collision energies, it appears to decompose via reaction channels other than that resulting in $\mathrm{N}_{2} \mathrm{H}^{+}$formation.
\end{abstract}

\section{INTRODUCTION}

We recently reported ${ }^{1}$ that the exoergic ion-molecule reaction

$$
\mathrm{Ar}^{+}+\mathrm{CH}_{4}-\mathrm{ArH}^{+}+\mathrm{CH}_{3}(\Delta H \cong-1.7 \mathrm{eV})
$$

demonstrates two rather uncommon features: (1) the excitation function (reaction cross section as a function of translational energy) appears to possess a threshold at about $0.1 \mathrm{eV}$, whereas nearly all exoergic reactions of positive ions have been found to proceed with no activation energy ; (2) the most probable value of the product translational energy is about $0.1 \mathrm{eV}$ lower than the value predicted by the spectator stripping model, ${ }^{3}$ exactly the opposite of the behavior observed for a number of exoergic hydrogenic-transfer ion-molecule reactions. ${ }^{4}$

We suggested ${ }^{5}$ that these two phenomena are related, both being manifestations of a basin in the potential energy hypersurface for the reaction. The unexpectedly low product translational energy results from $\mathrm{ArH}^{+}-\mathrm{CH}_{3}$ attraction and the consequent product deceleration as translational energy is converted into potential energy. Direct reaction is possible only if the collision energy is high enough that the products retain sufficient momentum to overcome this attractive potential and to separate completely. ${ }^{6}$ Failure to separate in a direct manner leads to the formation of an $\mathrm{ArCH}_{4}^{+}$complex which preferentially decomposes via reaction channels other than $\mathrm{ArH}^{+}$formation, thereby causing the sharp decrease observed in the excitation function at the lowest collision energies.

Product velocity spectra for the exoergic reactions

$$
\mathrm{N}_{2}^{+}+\mathrm{CD}_{4} \rightarrow \mathrm{N}_{2} \mathrm{D}^{+}+\mathrm{CD}_{3}
$$

have been measured over the energy range $0.4-22 \mathrm{eV}$ (c. m.) by Henglein and co-workers. ${ }^{7}$ At collision energies less than $10 \mathrm{eV}$, they found that the most probable product translational energy was consistently $0.1-0.2$ eV lower than that predicted by the spectator stripping model, and they suggested that an $\mathrm{N}_{2} \mathrm{CD}_{4}^{+}$complex might be formed at collision energies of a few tenths of an $\mathrm{eV}$.
Because we attributed the unusual shape of the excitation function for Reaction (1) to dynamical restrictions, and because Reaction (2) was reported ${ }^{7}$ to exhibit nearly identical dynamical behavior, we sought to determine if Reaction (2) also exhibited a similarly shaped excitation function. Although Mahan and co-workers ${ }^{8}$ have measured reaction cross sections and product velocity vector distributions for Reaction (2) over the energy range 10.5-25. $0 \mathrm{eV}$ (c. m.) and for the reaction

$$
\mathrm{N}_{2}^{+}+\mathrm{CH}_{4} \rightarrow \mathrm{N}_{2} \mathrm{H}^{+}+\mathrm{CH}_{3}
$$

over the energy range $9.1-47.3 \mathrm{eV}$ (c. $\mathrm{m}$. ), no information on the cross sections at energies less than $9 \mathrm{eV}$ has been published.

We report here cross sections and product velocity distributions for Reaction (2) over the energy range 0.65-19 eV (c. m.), and cross sections for Reaction (3) over the range $0.72-35 \mathrm{eV} \mathrm{c.m}$.

\section{EXPERIMENTAL}

\section{A. Apparatus}

The instrument used in this study is a single beamcollision chamber type of chemical accelerator with product velocity and angular analysis. Ions, formed by electron impact, are focused into a nearly monoenergetic beam of variable energy $(0.5-100 \mathrm{eV} \mathrm{lab})$ by a system of electrostatic lenses. This collimated beam passes through the collision chamber containing the neutral target gas, the pressure of which is measured by a capacitance manometer. The ion gun can be rotated about the center of the collision chamber, permitting the fixed detector to measure scattered product at various angles. Those ions leaving the collision chamber at the selected angle pass through a rectangular detection slit, a retarding potential energy analyzer, and a set of strong focusing quadrupole lenses. Mass analysis of these ions is performed with a $30 \mathrm{~cm}, 90^{\circ}$ deflection magnetic sector analyzer of a Nuclide mass spectrometer. The individual components of this instrument and the experimental procedures involved in data collec- 
tion have been described in detail elsewhere. ${ }^{5,9}$

\section{B. Internal states of the reactants}

The $\mathrm{N}_{2}^{+}$is produced by impact of $70 \mathrm{eV}$ electrons on $\mathrm{N}_{2}$, so that the primary beam contains $\mathrm{N}_{2}^{+}$with a distribution of internal energies (electronic, vibrational, and rotational). A study of optical emission from the decay of long-lived, excited states of $\mathrm{N}_{2}^{+}$produced by impact of $63 \mathrm{eV}$ electrons of $\mathrm{N}_{2}$ indicated that (1) most $(\sim 87 \%)$ of the emission is produced by $A^{2} \Pi_{u}-X^{2} \Sigma_{z}^{+}$transitions; (2) about $25 \%, 0.7 \%$, and $0.3 \%$ of the $\mathrm{N}_{2}^{+}$is initially produced in the $A^{2} \Pi_{u}, v^{\prime}=2-9$ levels, $v^{\prime}=10-19$ levels, and $v^{\prime}=20-30$ levels, respectively; and (3) excited state lifetimes were on the order of 6-7 $\mu \mathrm{sec} .^{10}$ In our apparatus, however, the 5-10 $\mu$ sec flight time from the extraction aperture to the collision chamber, plus the undetermined time spent in the ionization chamber before extraction, undoubtedly reduce the fraction of $\mathrm{N}_{2}^{+}$ ions in excited states below these initial values. The exact internal energy distribution of the reactant ions must, therefore, be considered as somewhat uncertain. The problems introduced by this uncertainty are recognized $^{11}$ and will be discussed in a later section.

Recent equilibrium studies performed with a flowing afterglow indicate that the proton affinity of $\mathrm{N}_{2}$ is 4.85 eV. ${ }^{12}$ With values of 13.60 and $15.57 \mathrm{eV}^{13}$ for the ionization potentials of $\mathrm{H}$ and $\mathrm{N}_{2}$, respectively, one obtains the value of $6.82 \mathrm{eV}$ for the energy required to dissociate $\mathrm{N}_{2} \mathrm{H}^{+}$into $\mathrm{H}$ and $\mathrm{N}_{2}^{+}\left(X^{2} \Sigma_{z}^{+}\right)$. Assuming the value $D_{0}\left(\mathrm{H}-\mathrm{CH}_{3}\right)$ $=4.47 \mathrm{eV},{ }^{14}$ the exoergicity of Reaction (3) is $\Delta E_{0}$ $=-2.35 \mathrm{eV}$ for ground state reactants.

\section{CALCULATIONS}

\section{A. Translational exoergicity $Q$}

Defined as the net difference between the final and inital translational energies,

$$
Q=E^{\prime}-E,
$$

the translational exoergicity describes the partitioning of reaction energy between internal and translational modes of the products. The initial energy $E$ is obtained from

TABLE I. Kinematic data for the reaction $\mathrm{N}_{2}^{+}+\mathrm{CD}_{4} \rightarrow \mathrm{N}_{2} \mathrm{D}^{+}$ $+\mathrm{CD}_{3}$.

\begin{tabular}{lllll}
\hline \hline $\begin{array}{l}\text { Most probable } \\
\text { lab energy of } \\
\mathrm{N}_{2}^{+}(\mathrm{eV})\end{array}$ & $\begin{array}{l}\text { Most probable } \\
\text { lab energy of } \\
\mathrm{N}_{2} \mathrm{D}^{+}(\mathrm{eV})\end{array}$ & $\begin{array}{l}\text { Collision } \\
\text { energy, } \\
E(\mathrm{eV})\end{array}$ & $\begin{array}{l}\text { Translational } \\
\text { exoergicity } \\
Q(\mathrm{eV})\end{array}$ & $\begin{array}{l}\text { Velocity } \\
\text { ratio }\end{array}$ \\
\hline 1.55 & 1.33 & 0.645 & -0.216 & $\begin{array}{l}u_{\mathrm{N}_{2} \mathrm{D}^{+}} \\
u_{\mathrm{N}_{2}^{+}}\end{array}$ \\
2.36 & 2.19 & 0.982 & -0.171 & 0.747 \\
3.33 & 3.04 & 1.39 & -0.34 & 0.833 \\
3.43 & 3.00 & 1.43 & -0.42 & 0.816 \\
3.95 & 3.61 & 1.65 & -0.35 & 0.769 \\
4.36 & 4.05 & 1.82 & -0.32 & 0.815 \\
4.49 & 3.96 & 1.87 & -0.52 & 0.833 \\
5.38 & 4.96 & 2.24 & -0.43 & 0.776 \\
6.06 & 5.45 & 2.52 & -0.61 & 0.825 \\
8.50 & 7.74 & 3.54 & -0.76 & 0.800 \\
13.5 & 12.6 & 5.61 & -0.91 & 0.812 \\
21.6 & 20.3 & 9.00 & -1.32 & 0.839 \\
28.7 & 26.9 & 11.9 & -1.78 & 0.846 \\
38.8 & 36.7 & 16.2 & -2.11 & 0.845 \\
45.7 & 43.5 & 19.0 & -2.19 & 0.855 \\
\hline
\end{tabular}

the most probable laboratory energy of the incident $\mathrm{N}_{2}^{+}$, with the target molecule assumed to be stationary. The final energy was obtained by the following procedure: the product ion distribution was scanned to determine the angle of maximum intensity, and the energy distribution was then measured at the angle of maximum ion intensity. This energy spectrum was then converted to the corresponding Cartesian ${ }^{15}$ spectrum by multiplying the intensity at each point by the over-all Jacobian factor of $1 / v$. Values for $E^{\prime}$ and hence $Q$ were calculated from the point of maximum intensity in the Cartesian velocity spectrum.

For ground state reactants, the maximum value of $Q$ occurs when all available reaction energy appears as product translation: $Q_{\max }=-\Delta E_{0}=2.35 \mathrm{eV}$. A pseudominimum value for $Q$ can be assigned if one assumes all product excitation is contained in the ionic product. By requiring that $E_{\mathrm{int}}^{\prime}<D_{0}\left(\mathrm{~N}_{2}-\mathrm{H}^{+}\right)$for stable product formation, one obtains $Q_{\min }=-\Delta E_{0}-D_{0}\left(\mathrm{~N}_{2}-\mathrm{H}^{+}\right)=-2.5 \mathrm{eV}$. Observation of $\mathrm{N}_{2} \mathrm{H}^{+}$at $Q$ values more negative than $Q_{\min }$ requires that the methyl fragment be produced with internal excitation.

\section{B. Reaction cross section $\sigma_{R}$}

The reaction cross section is calculated from the equation

$$
\sigma_{R}=\frac{I_{C} / I_{A}}{n_{B} L} K(f, T),
$$

where $I_{C}$ is the total reactively scattered product ion intensity, $I_{A}$ is the transmitted primary ion intensity, $n_{B}$ is the number density of target molecules in the collision chamber, and $L$ is the collision path length. The quantity $I_{C} / I_{A} n_{B} L$ is, therefore, the familiar thin-target formula often used to calculate reaction cross sections. The term

$$
K(f, T)=\left\{\begin{array}{cc}
1 & \text { if } f=1 \\
(f-1) \ln T /\left(T^{f-1}-1\right) & \text { if } f \neq 1
\end{array}\right.
$$

corrects for attenuation of the reactant and product beams. ${ }^{5 \mathrm{~b}} T$ is the fraction of the primary ion beam that passes through the collision chamber, $I_{A} / I_{A}^{0}$, and $f$ is the ratio of the integral cross section for attenuation of $A$ by $B$ to that for attenuation of $C$ by $B$.

As before, ${ }^{5 b, 9}$ the ratio of total ion currents is given

$$
\frac{I_{C}}{I_{A}}=\frac{I_{C}\left(0^{\circ}\right) K_{C}}{I_{A}\left(0^{\circ}\right) K_{A}} K_{1} K_{2}
$$

where $I_{C}\left(0^{\circ}\right)$ and $I_{A}\left(0^{\circ}\right)$ are the observed ion intensities at the angular maximum, $K_{C}$ and $K_{A}$ correct for differences in collection efficiency caused by differences in angular distributions, $K_{1}$ corrects for differences in multiplier gain, and $K_{2}$ corrects for any broadening of the mass spectral peak of ions formed with a wide distribution of kinetic energies.

Because the primary ion beam is not mass selected, it contains a component of $m / e=29$, due to ${ }^{14} \mathrm{~N}^{15} \mathrm{~N}^{+}$. In studies of Reaction (3), the actual $\mathrm{N}_{2} \mathrm{H}^{+}$intensity was obtained by subtracting from the observed $\mathrm{m} / e 29$ intensity 


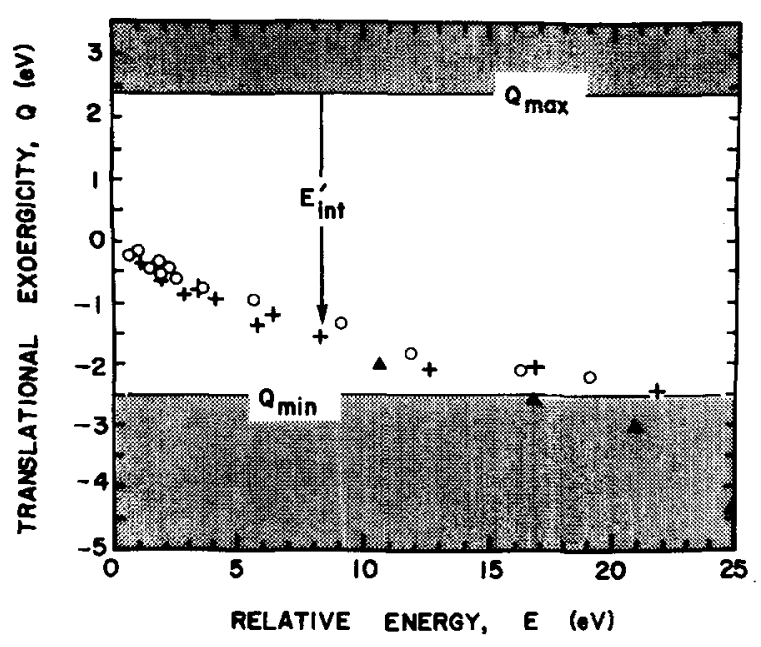

FIG. 1. Translational exoergicity $Q$ vs initial relative energy $E$ for the reaction $\mathrm{N}_{2}^{+}\left(\mathrm{CD}_{4}, \mathrm{CD}_{3}\right) \mathrm{N}_{2} \mathrm{D}^{+}$. Open circles indicate the present results; crosses represent the results of Henglein and co-workers ${ }^{7}$; triangles indicate the data of Mahan and coworkers. ${ }^{8}$ (Several low energy points are omitted for the sake of clarity. They are included in Fig. 2.) Upper limit $Q_{\max }$ is determined by the energy released in the reaction, $-\Delta E_{0}$ $=2.35 \mathrm{eV}$. Lower limit $Q_{\mathrm{min}}$ is determined by the dissociation energy of $\mathrm{N}_{2} \mathrm{D}^{+}$and the assumption that all of the product internal excitation resides in the ionic product.

that contribution arising from ${ }^{14} \mathrm{~N}^{15} \mathrm{~N}^{+}$. This contribution was assumed to be proportional to the observed primary ion $(m / e=28)$ intensity,

$$
I_{\mathrm{N}_{2} \mathrm{H}^{+}}(\Theta)=I_{29}(\Theta)-k \cdot I_{28}(\Theta)
$$

The proportionality constant $k$, determined from the $m / e$ 29 intensity with no $\mathrm{CH}_{4}$ in the collision chamber, was found to be $(7.4 \pm 0.1) \times 10^{-3}$. This value is in good agreement with the values of $7.32 \times 10^{-3}$ expected from the natural abundance of ${ }^{15} \mathrm{~N} .{ }^{16}$

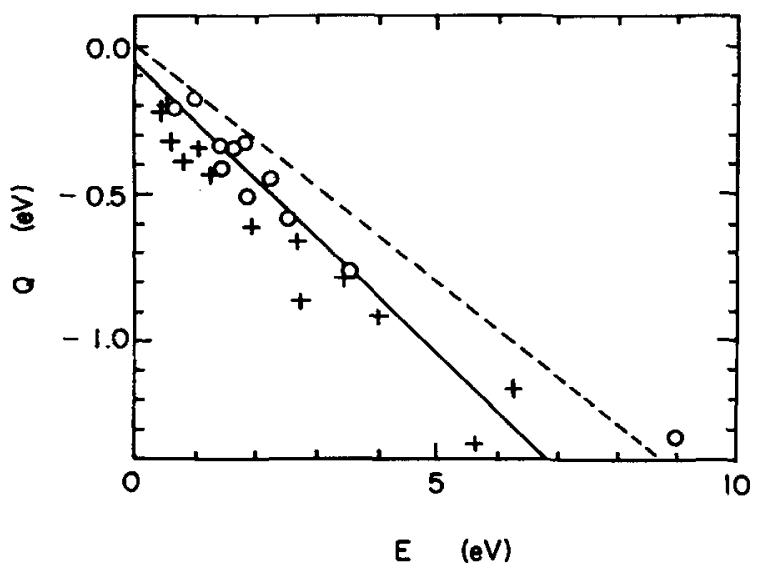

FIG. 2. $Q$ vs $E$ for the reaction $\mathrm{N}_{2}^{+}\left(\mathrm{CD}_{4}, \mathrm{CD}_{3}\right) \mathrm{N}_{2} \mathrm{D}^{+}$over the energy range $0-10 \mathrm{eV}(\mathrm{CM})$. Present results are shown by open circles and those of Henglein ${ }^{7}$ by crosses. Dashed line is the prediction of the spectator stripping model. The solid line represents the best linear fit to the present data from a least squares analysis.

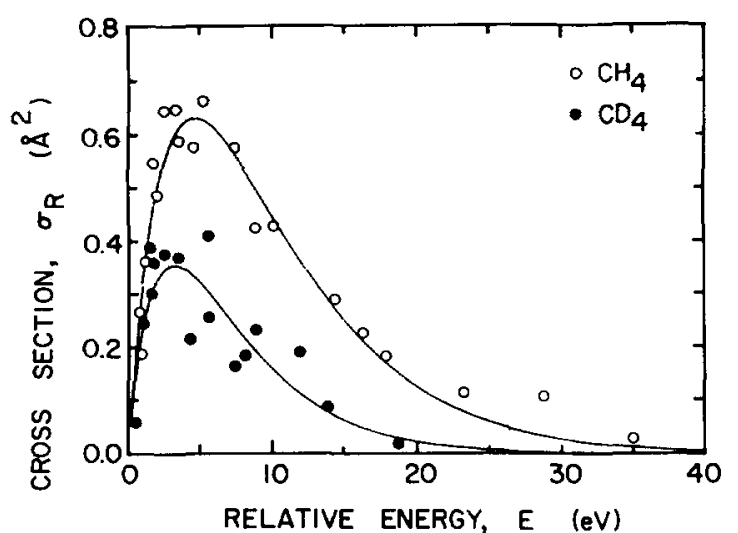

FIG. 3. Integral reaction cross sections $\sigma_{R}$ vs initial relative energy $E$ for the reactions $\mathrm{N}_{2}^{+}\left(\mathrm{CH}_{4}, \mathrm{CH}_{3}\right) \mathrm{N}_{2} \mathrm{H}^{*}$ (open circles) and $\mathrm{N}_{2}^{+}\left(\mathrm{CD}_{4}, \mathrm{CD}_{3}\right) \mathrm{N}_{2} \mathrm{D}^{+}$(solid circles). The values of the cross sections, calculated from Eqs. (5) and (7), are listed in Table II. The solid lines represent an empirical fit [Eq. (9)] to the experimental data, using the parameters given in Table III.

\section{RESULTS}

\section{A. Energy partitioning}

The kinematic data obtained for Reaction (2) is summarized in Table I, which lists the laboratory energy of the reactant ion and the laboratory energy of the product ion calculated from the velocity of maximum intensity in the $\mathrm{N}_{2} \mathrm{D}^{+}$Cartesian velocity spectrum. The translational exoergicity and the ratio of the center of mass velocity of the ionic product to the center of mass velocity of the reactant ion, $u_{\mathrm{N}_{2} \mathrm{D}^{+}} / u_{\mathrm{N}_{2}^{+}}$, are also presented in Table I. The translational exoergicity is plotted vs the center of mass collision energy in Figs. 1 and 2.

\section{B. Cross sections}

Multiplier gains were determined for $\mathrm{N}_{2}^{+}, \mathrm{N}_{2} \mathrm{H}^{+}$, and $\mathrm{N}_{2} \mathrm{D}^{+}$by the method described in Ref. $5 \mathrm{~b}$. The following results were obtained: for $\mathrm{Ar}^{+} / \mathrm{ArH}^{+}, K_{2}=0.88 \pm 0.01$; for $\mathrm{Ar}^{+} / \mathrm{ArD}^{+}, K_{1}=0.97 \pm 0.01$. The energy dispersion correction term, $K_{2}$, was found to be unity under the conditions of these experiments. ${ }^{5 b}$

The cross section data for Reactions (2) and (3) are summarized in Table II. The correction factors for differences in the primary and secondary ion angular distributions, $K_{C} / K_{A}$, were calculated by integration of the observed laboratory distributions by the method described in Ref. 5b. Correction factors for attenuation of the primary ion beam, $K(0, T)$, have been calculated from Eq. (6) under the assumption ${ }^{17}$ that $f=0$. The integral reaction cross sections, $\sigma_{R}$, were calculated from Eq. (5), using the ratio $I_{C} / I_{A}$ obtained from Eq. (7). The experimental uncertainty in $\sigma_{R}$ is judged to be $\pm 40 \%$. The excitation functions $\left(\sigma_{R}\right.$ vs $E$ ) for Reactions (2) and (3) are presented in Fig. 3.

It was found ${ }^{5 b}$ that the over-all shape of the excitation function for Reaction (1) could be described by an empirically derived expression of the general form

$$
\sigma_{R}(E)=\left\{\begin{array}{cl}
0 & \text { if } E \leq E_{0} \\
A\left(E-E_{0}\right)^{B} e^{-C\left(E-E_{0}\right)} & \text { if } E>E_{0},
\end{array}\right.
$$


TABLE II. Integral cross sections for reactions of the type $\mathrm{N}_{2}^{+}+\mathrm{CY}_{4} \rightarrow \mathrm{N}_{2} \mathrm{Y}^{+}+\mathrm{CY}_{3}$.

\begin{tabular}{|c|c|c|c|c|c|}
\hline $\begin{array}{l}\text { Most probable } \\
\text { lab energy of } \\
N_{2}^{+} \\
E_{1 \mathrm{ab}}(\mathrm{eV}) \\
\end{array}$ & $\begin{array}{l}\text { Most probable } \\
\text { relative } \\
\text { energy } \\
E(\mathrm{eV})\end{array}$ & $\begin{array}{l}\text { Pressure } \\
\text { of } \mathrm{CY}_{4} \\
\left(10^{-3} \text { torr }\right)\end{array}$ & $\begin{array}{l}\text { Relative } \\
\text { collection } \\
\text { efficiencies } \\
K_{C} / K_{A} \\
\end{array}$ & $\begin{array}{l}\text { Transmission } \\
\text { factor } \\
K(0, T)\end{array}$ & $\begin{array}{l}\text { Integral } \\
\text { reaction } \\
\text { cross section } \\
\sigma_{R}\left(10^{-16} \mathrm{~cm}^{2}\right)\end{array}$ \\
\hline \multicolumn{6}{|c|}{ A. $\mathrm{N}_{2}^{+}+\mathrm{CH}_{4} \rightarrow \mathrm{N}_{2} \mathrm{H}^{+}+\mathrm{CH}_{3}$} \\
\hline 1.97 & 0.72 & 1.59 & 4.25 & 0.431 & 0.257 \\
\hline 2.95 & 1.07 & 1.62 & 3.62 & 0.455 & 0.190 \\
\hline 3.60 & 1.31 & 1.50 & 3.35 & 0.480 & 0.362 \\
\hline 4.87 & 1.77 & 1.65 & 2.85 & 0.534 & 0.550 \\
\hline 5.50 & 2.00 & 1.23 & 1.96 & 0.556 & 0.487 \\
\hline 6.90 & 2.51 & 1.70 & 2.25 & 0.592 & 0.651 \\
\hline 9.10 & 3.31 & 1.70 & 2.15 & 0.639 & 0.651 \\
\hline 9.90 & 3.60 & 1.33 & 2.08 & 0.655 & 0.589 \\
\hline 12.60 & 4.58 & 1.49 & 2.00 & 0.678 & 0.578 \\
\hline 14.40 & 5.24 & 1.40 & 1.98 & 0.695 & 0.663 \\
\hline 20.3 & 7.38 & 1.45 & 1.70 & 0.730 & 0.575 \\
\hline 24.3 & 8.84 & 1.00 & 1.60 & 0.740 & 0.416 \\
\hline 28.1 & 10.2 & 1.51 & 1.50 & 0.751 & 0.424 \\
\hline 39.7 & 14.4 & 1.58 & 1.25 & 0.777 & 0.291 \\
\hline 44.8 & 16.3 & 1.40 & 1.19 & 0.784 & 0.224 \\
\hline 48.8 & 17.8 & 1.58 & 1.18 & 0.788 & 0.182 \\
\hline 63.8 & 23.2 & 1.71 & 1.16 & 0.795 & 0.119 \\
\hline 79.2 & 28.8 & 1.83 & 1.10 & 0.803 & 0.115 \\
\hline 96.5 & 35.1 & 1.88 & 1.03 & 0.814 & 0.033 \\
\hline \multicolumn{6}{|c|}{ B. $\mathrm{N}_{2}^{+}+\mathrm{CD}_{4} \rightarrow \mathrm{N}_{2} \mathrm{D}^{+}+\mathrm{CD}_{3}$} \\
\hline 1.55 & 0.645 & 1.20 & 3.44 & 0.407 & 0.057 \\
\hline 2.36 & 0.982 & 1.20 & 4.25 & 0.455 & 0.240 \\
\hline 3.43 & 1.43 & 1.00 & 5.80 & 0.493 & 0.388 \\
\hline 3.95 & 1.65 & 1.01 & 9.84 & 0.520 & 0.298 \\
\hline 4.49 & 1.87 & 1.20 & 4.50 & 0.548 & 0.358 \\
\hline 6.06 & 2.52 & 1.43 & 3.44 & 0.592 & 0.375 \\
\hline 8.50 & 3.54 & 1.35 & 3.63 & 0.648 & 0.370 \\
\hline 10.6 & 4.42 & 1.18 & 3.34 & 0.678 & 0.209 \\
\hline 13.5 & 5.61 & 1.1 .5 & 2.37 & 0.698 & 0.414 \\
\hline 13.5 & 5.61 & 1.14 & 2.45 & 0.698 & 0.251 \\
\hline 17.7 & 7.37 & 1.39 & 2.39 & 0.719 & 0.155 \\
\hline 19.8 & 8.25 & 1.16 & 2.11 & 0.730 & 0.183 \\
\hline 21.6 & 9.00 & 1.39 & 1.90 & 0.744 & 0.235 \\
\hline 28.7 & 11.9 & 1.25 & 1.77 & 0.766 & 0.197 \\
\hline 33.3 & 13.9 & 1.29 & 1.69 & 0.773 & 0.084 \\
\hline 45.7 & 19.0 & 1.50 & 2.17 & 0.788 & 0.018 \\
\hline
\end{tabular}

where $E_{0}$ is the apparent translational energy threshold (taken as $0.1 \mathrm{eV}$ ); $E$ is the relative translational energy; and $A, B$, and $C$ are parameters whose values are chosen to give the best fit to the experimental data. As shown by the solid lines in Fig. 3, Eq. (9) also provides a reasonable description of the energy dependence of the integral cross sections for Reactions (2) and (3). The best values of the parameters $A, B$, and $C$, determined by a least squares analysis of the data, are listed in Table III. We must repeat, however, that Eq. (9) has no theoretical significance; it simply provides a convenient analytic functional form which summarizes the experimental data.

\section{DISCUSSION}

\section{A. Reaction dynamics}

The $\mathrm{N}_{2} \mathrm{D}^{+}$product was found to be strongly forward scattered with respect to the center of mass, indicating that Reaction (2) is dominated by a direct mechanism (i.e., an impulsive type of interaction occurring on a time scale comparable to one rotational period) over the energy range studied $(0.65-19 \mathrm{eV})$.

The dependence of energy partitioning upon collision energy for the reaction $\mathrm{N}_{2}^{+}\left(C_{4}, C_{3}\right) \mathrm{N}_{2} D^{+}$(shown in Fig. 1) is very similar to that previously reported ${ }^{52}$ for the reaction $\mathrm{Ar}^{+}\left(\mathrm{CD}_{4}, \mathrm{CD}_{3}\right) \mathrm{ArD}^{+}$. The present data, which are in good agreement with those reported by Henglein and co-workers, ${ }^{7}$ indicate that the most probable reaction mechanism at low to intermediate collision energies $(E<10 \mathrm{eV})$ is one in which (1) all of the reaction exorgicity appears as internal energy of the products, and (2) product excitation increases linearly with collision energy at very nearly the rate predicted by the spectator stripping model. ${ }^{3}$

At higher collision energies, Henglein's data and the present results indicate that product excitation becomes nearly independent of the collision energy, with $E_{\text {int }}^{\prime}$ asymptotically approaching a limiting value of about 4.7 eV. This value is very nearly equal to the proton affinity of $N_{2}$, thereby implying that the most probable process does not involve the transfer of reaction energy 
TABLE III. Parameters for the excitation function. ${ }^{a}$

\begin{tabular}{llll}
\hline Reaction & $A\left(\mathrm{~A}^{2}\right)$ & $B$ & $C(\mathrm{eV})^{-1}$ \\
\hline $\mathrm{N}_{2}^{+}\left(\mathrm{CH}_{4}, \mathrm{CH}_{3}\right) \mathrm{N}_{2} \mathrm{H}^{+}$ & 0.412 & 0.840 & 0.186 \\
$\mathrm{~N}_{2}^{+}\left(\mathrm{CD}_{4}, \mathrm{CD}_{3}\right) \mathrm{N}_{2} \mathrm{D}^{*}$ & 0.323 & 0.764 & 0.249 \\
\hline
\end{tabular}

${ }^{2}$ The excitation function is assumed to be given by the expression $\sigma_{R}(E)=A\left(E-E_{0}\right)^{B} e^{-C\left(E-E_{0}\right)}$. The parameters were determined by a least squares analysis of the experimental data, with $E_{0}$ taken as $0.1 \mathrm{eV}$.

to the internal degrees of freedom of the methyl fragment and that the asymptotic approach to $E_{\text {int }}^{\prime} \simeq 4.7 \mathrm{eV}$ is caused by excitation of $\mathrm{N}_{2} \mathrm{D}^{+}$to its dissociation limit. ${ }^{18}$ At a given collision energy, however, the products possess a distribution of internal energies about the most probable value depicted in Fig. 1. At the higher collision energies, we find significant product intensity in regions of velocity space for which $E_{1 \mathrm{nt}}^{\prime}>D_{0}\left(\mathrm{~N}_{2}-D^{+}\right)$, so that stable $\mathrm{N}_{2} \mathrm{D}^{+}$production is possible only if the methyl fragment possesses considerable internal excitation. Indeed, Mahan and co-workers ${ }^{8}$ report $Q$ values (see Fig. 1) that indicates the most probable process is one producing appreciable excitation of the methyl fragment.

Although the energy dependence of the energy partitioning is approximated by the spectator stripping model for $E \leqslant 10 \mathrm{eV}$, the measured values of the most probable product translational energy are consistently lower by about $0.1 \mathrm{eV}$ than the values predicted by this model (see Fig. 2). These negative deviations, which have also been reported for the reaction $\mathrm{Ar}^{+},\left(\mathrm{CD}_{4}\right.$, $\left.\mathrm{CD}_{3}\right) \mathrm{ArD}^{+}$, are assumed to be indicative of an attractive potential between $\mathrm{N}_{2} \mathrm{D}^{+}$and $C \mathrm{CD}_{3}$ which decelerates the products as they separate. ${ }^{5 b}$ This attraction will produce a basin in the potential energy hypersurface for the reaction, the existence of which is consistent with Henglein's suggestion ${ }^{7}$ than an $\mathrm{N}_{2} \mathrm{CH}_{4}^{+}$intermediate complex might be formed at very low collision energies.

\section{B. Excitation functions}

The excitation functions for Reactions (2) and (3) have three interesting features: (1) The cross sections are approximately 100 times smaller than the cross sections for the corresponding reactions with molecular hydrogen. (2) The excitation functions for these exoergic reactions appear to possess a translational energy threshold. (3) There is a large isotope effect favoring abstraction of $\mathrm{H}$ over $\mathrm{D}$. Identical behavior has been observed for the reaction of $\mathrm{Ar}^{+}$with methane. ${ }^{5 \mathrm{~b}}$

The small cross sections for the $\mathrm{H}$-atom abstraction reactions are presumably a result of competion from the very fast dissociative charge transfer reactions that occur in these systems. ${ }^{19}$ Rate constants on the order of $10^{-9} \mathrm{~cm}^{3} / \mathrm{mol}-\mathrm{sec}$ have been measured for charge transfer in the $\mathrm{Ar}^{+}-\mathrm{CH}_{4}$ system, ${ }^{20}$ and somewhat larger values have been reported for the $\mathrm{N}_{2}^{+}-\mathrm{CH}_{4}$ system. ${ }^{21}$

The apparent translational energy threshold for the formation of $\mathrm{N}_{2} \mathrm{H}^{+}$(or $\mathrm{N}_{2} \mathrm{D}^{+}$) can be interpreted as a threshold for the reaction via the stripping mechanism. As discussed above (and, in more detail, in Ref. 5), the reaction kinematics indicate that the potential energy hypersurface contains a basin from which the products can escape only with difficulty, particularly at the lowest collision energies. Although the abstraction reaction is dominated by a direct mechanism over the entire energy range studied, the measured product velocity distributions indicate that at collision energies less than about $0.1 \mathrm{eV}$ the products do not retain sufficient momentum to escape the basin and to separate completely. The sudden decrease in $\mathrm{N}_{2} \mathrm{H}^{+}$yield at low collision energies suggest that if an $\mathrm{N}_{2} \mathrm{CH}_{4}^{+}$intermediate complex is formed, it decomposes either back to the reactants or forward via reaction channels (e.g., dissociative charge transfer) other than $\mathrm{N}_{2} \mathrm{H}^{+}$formation.

The large isotope effect favoring abstraction of $\mathrm{H}$ over $D$, particularly at high collision energies, was first reported for these reactions by Mahan and co-workers. ${ }^{8}$ The magnitude and the energy dependence of this isotope effect found in the present study agree well with this earlier work. The absolute values of the reaction cross sections reported by Mahan, however, are very nearly 10 times larger than the values reported here. No explanation has been found for this discrepancy. The validity of the technique employed in the present study was tested by measuring the reaction cross sections for the reactions $\mathrm{N}_{2}^{+}\left(\mathrm{D}_{2}\right.$, D) $\mathrm{N}_{2} \mathrm{D}^{+}$and $\mathrm{N}_{2}^{+}\left(\mathrm{H}_{2}, \mathrm{H}\right) \mathrm{N}_{2} \mathrm{H}^{+}$. Because the ionic products of these reactions have laboratory angular and velocity distributions very similar to those of the ionic products from Reactions (2) and (3), respectively, collection efficiencies should be very similar. The results obtained for these standard reactions are in excellent agreement with the data reported by other laboratories (see Ref. 9), indicating that the technique employed in the present study for measuring absolute cross sections contains no serious systematic error.

\section{Future work}

The measured cross sections for these reactions may well depend upon the internal energy possessed by the reactant ion at the time of collision. This internal energy distribution, in turn, will depend both upon the ionization conditions and upon the delay time between ion formation and reaction. ${ }^{11}$ It is conceivable, for example, that $\mathrm{N}_{2} \mathrm{H}^{+}$is formed predominantly by the reaction of $\mathrm{N}_{2}^{+}$in an electronically excited state (e.g., $A^{2} \Pi_{u}$ ), and that the apparent decrease in the reaction cross section is due to a decreased proportion of the excited state in the primary ion beam as the flight time from ion source to collision chamber exceeds the radiative lifetime for that excited state. However, the fact that similar threshold behavior was observed for the reaction of ground state $\mathrm{Ar}^{+}$with $\mathrm{CH}_{4}{ }^{5 \mathrm{~b}}$ leads us to doubt internal excitation of the $\mathrm{N}_{2}^{+}$is the cause of the translational energy threshold observed for Reactions (2) and (3). Nevertheless, the uncertainty with regard to the internal energy distribution of the reactant ions sufficiently complicates the interpretation of the present results that is would be very desirable to repeat these measurements under conditions which permit the internal energy of the $\mathrm{N}_{2}^{+}$to be well characterized. 
The suggestion made here that low-energy collisions result in the formation of an $\mathrm{N}_{2} \mathrm{CH}_{4}^{+}$complex which decomposes via various charge exchange channels implies the formation of $\mathrm{CH}_{3}^{+}$(and perhaps other) ions whose velocity vectors are symmetrically distributed about the center of mass. Charge exchange reactions with momentum transfer of this type have been reported for the $\mathrm{Ar}^{+}-\mathrm{CH}_{4}$ system, ${ }^{22}$ and it would be interesting to determine if they also occur in the $\mathrm{N}_{2}^{+}-\mathrm{CH}_{4}$ system.

\section{SUMMARY AND CONCLUSIONS}

The reactions $\mathrm{X}^{+}\left(\mathrm{CH}_{4}, \mathrm{CH}_{3}\right) \mathrm{XH}^{+}$, where $\mathrm{X}=\mathrm{Ar}$ or $\mathrm{N}_{2}$, exhibit the following characteristics: (1) The reactions are dominated by a direct mechanism over the entire energy range studied, $0.39-35 \mathrm{eV}$. (2) Energy partitioning is roughly approximated by the spectator stripping model, but negative deviations from this model are observed at the lower collision energies. (3) The excitation functions for these strongly exoergic reactions maximize at about $5 \mathrm{eV}$ (c. m.) and then decrease sharply at lower collision energies, appearing to possess a translational energy threshold at about $0.1 \mathrm{eV}$.

We suggest that features (2) and (3) are related; that the potential energy hypersurface for each of these reactions contains a basin which impedes product separation and which, at the lowest collision energies, results in the formation of an $\mathrm{XCH}_{4}^{+}$complex which preferentially decomposes via reaction channels other than $\mathrm{XH}^{+}$ formation.

\section{ACKNOWLEDGMENTS}

Acknowledgment is made to the donors of the Petroleum Reseach Fund, administered by the American Chemical Society, for partial support of this research. Additional support was provided by the Research Corporation and by the University of Kansas General Research Fund. The assistance of Mr. S. Chivalak in analyzing much of the data is gratefully acknowledged.

*Present address: Naval Research Laboratory, Washington, D. C. 20375.

†Present address: Department of Chemistry, Emory University, Atlanta, GA 30322 .

†Present address: Environmental Health Laboratory, 801 Harrison, Topeka, KS 66612.

${ }^{1}$ J. R. Wyatt, L. W. Strattan, S. C. Snyder, and P. M. Hierl,
J. Chem. Phys. 60, 3702 (1974).

${ }^{2}$ F. W. Lampe, J. L. Franklin, and F. H. Field, Prog. React. Kinet. 1, 84 (1961).

${ }^{3}$ A. Henglein, K. Lacmann, and G. Jacobs, Ber. Bunsenges. Phys. Chem. 69, 286, 292 (1965).

${ }^{4}$ See, for example, (a) J. L. Franklin and M. A. Haney, J. Phys. Chem. 73, 2857 (1969); (b) C. M. Connally and E. A. Gislason, Chem. Phys. Lett. 14, 103 (1972), and references cited therein.

${ }^{5}$ (a) J. R. Wyatt, L. W. Strattan, S. C. Snyder, and P. H. Hierl, J. Chem. Phys. 62, 2555 (1975); (b) J. R. Wyatt, L. W. Stratton, S. Chivalak, and P. M. Hierl, J. Chem. Phys, (to be published).

${ }^{6}$ J. C. Polanyi, Discuss. Faraday Soc. 44, 293 (1967).

${ }^{7}$ A. Ding, A. Henglein, D. Hyatt, and K. Lacmann, Z. Naturforsch. A 23, 2077 (1968).

${ }^{8}$ E. A. Gislason, B. H. Mahan, C. -w. Tsao, and A. S. Werner, J. Chem. Phys. 50, 142 (1969).

${ }^{9}$ P. M. Hierl, L. W. Strattan, and J. R. Wyatt, Int. J. Mass Spectrom. Ion Phys. 10, 385 (1973).

${ }^{10}$ W. B. Maier, II, and R. F. Holland, J. Chem. Phys. 59, 4501 (1973).

${ }^{11} \mathrm{M}$. Henchman, in Ion-Molecule Reactions, edited by J. L. Franklin (Plenum, New York, 1972), Vol. 1, pp. 101-259.

${ }^{12} \mathrm{H}$. I. Schiff and D. K. Bohme, Int. J. Mass Spectrom. Ion Phys. 16, 167 (1975).

${ }^{13}$ Natl. Bur. Stand. Ref. Data Ser. 26, (1969).

${ }^{14}$ L. V. Gurvich, G. A. Khachkuruzov, V. A. Medvedev, I. V. Veits, G. A. Bergman, V. S. Yungman, N. P. Rtisheheva, and L. F. Kuratova, Thermodynamic Properties of Individual Substances, Izd. AN SSSR, Moscow (1962).

${ }^{15}$ R. Wolfgang and R. J. Cross, J. Phys。Chem. 73, 743 (1969).

${ }^{16}$ G. Friedlander, J.W. Kennedy, and J. M. Miller, Nuclear and Radiochemistry (Wiley, New York, 1966).

${ }^{17}$ The variable $f$ is the ratio of the integral cross section for attenuation of $\mathrm{N}_{2} \mathrm{H}^{+}$by $\mathrm{CH}_{4}$ to that for attenuation of $\mathrm{N}_{2}^{+}$by $\mathrm{CH}_{4}$ (or the deuterated variants thereof). The rationale for assuming $f=0$ is discussed in Ref. 5b.

${ }^{18}$ This explanation has been proposed to explain similar behavior in several other ion-molecule reactions. See, for example, (a) R. L. Champion, L. D. Doverspike, and T. L。 Bailey, J. Chem. Phys. 45, 4385 (1966); (b) W. R. Gentry, E. A. Gislason, Y. -t. Lee, B. H. Mahan, and C. -w. Tsao, Discuss. Faraday Soc. 44, 137 (1967); (c) W. R. Gentry, E. A. Gislason, B. H. Mahan, and C. $-w_{0}$ Tsao, J. Chem. Phys. 49, 3058 (1968); (d) J. C. Tully, Z. Herman, and R. Wolfgang, ibid. 54, 1730 (1971); (e) A. Henglein, Adv. Chem. Ser. 58, 63 (1966).

${ }^{19}$ (a) V. L. Talrose and G. V. Karachevtsev, Adv. Mass. Spectrom. 3, 211 (1966); (b) A. J. Masson, K. Birkinshaw, and M. J. Henchman, J. Chem. Phys. 50, 4112 (1969)。

${ }^{20}$ See footnote 18 in Ref. 5 a.

${ }^{21}$ H. von Koch, Ark. Fys. 28, 529 (1965).

${ }^{22}$ A. J. Masson, K. Birkinshaw, and M. J. Henchman, J. Chem. Phys. 50, 4112 (1969). 